\title{
Desenvolvimento sustentável e algumas vulnerabilidades geradas pelo não atendimento de necessidades básicas
}

\section{Sustainable development and specific vulnerabilities generated by the lack of basic necessities}

\section{El desarrollo sostenible y algunas de las vulnerabilidades generadas por la falta de atención a las necesidades básicas}

Wilma de Assis, doutora em Meio Ambiente e Desenvolvimento pela Universidade Federal do Paraná (UFPR). Endereço: Rua Nova Iguaçu, 897 - Recreio. CEP: 28890-000 - Rio das Ostras, RJ. E-mail: wilmadeassis@hotmail.com.

Maria Elisa Zanella, doutora em Meio Ambiente e Desenvolvimento pela UFPR. Endereço: Rua Monsenhor Otávio de Castro, 677, apto 303 - Fástima. CEP: 60050-150 - Fortaleza, CE. E-mail: elisazv@terra.com.br.

\section{Resumo}

O tema deste artigo se insere no contexto atual de transição, ou de tentativas de transição, de um modelo de desenvolvimento considerado insustentável para outro, sustentável. Analisa essa transição pela presença de organizações internacionais atuando em prol da humanização do desenvolvimento e pela existência de novos indicadores de desenvolvimento. Tem por objetivo abordar as vulnerabilidades individuais/sociais possiveis de serem geradas pelo não atendimento de necessidades humanas. Utiliza como método a sobreposição dos conceitos de desenvolvimento, necessidades e vulnerabilidades, recorrendo a algumas disposições metodológicas da teoria da complexidade. Conclui sobre a importância de abordagens econômicas aproximarem-se da complexidade, utilizarem os novos 
indicadores de sustentabilidade e de valores humanos. Considera a proposição de que, quando a economia muda, o desenvolvimento muda. Quando o ser humano muda, a economia e o desenvolvimento também mudam.

Palavras-chave: Vulnerabilidades. Necessidades. Desenvolvimento. Sustentabilidade.

\section{Abstract}

This study was conducted within the framework of the transition, or attempted transition, from a model of development considered unsustainable to one characterized by sustainability. This transition is analyzed based on the presence of the international organizations that work towards the humanization of the development process and the existence of new indices of development. The principal objective is to identify the potential social or individual vulnerabilities generated by the lack of basic necessities. The study approaches this question through an overlap of the concepts of development, necessities, and vulnerabilities, drawing on a number of methodological procedures derived from Complexity Theory. The results of the study indicate the need for economic approaches to assimilate the complexity of the problem, using new indices of sustainability and human values. In particular, the study concludes that when the economy changes, the development process also changes. When human beings change, the economy and development also change.

Keywords: Vulnerabilities. Necessities. Development. Sustainability.

\section{Resumen}

El tema de este artículo es parte del contexto actual de transición, o de los intentos de transición, de un modelo de desarrollo considerado insostenible para otro, sostenible. Analiza esta transición por la presencia de organizaciones internacionales que trabajan por la 
humanización del desarrollo y por la existencia de nuevos indicadores de desarrollo. Su objetivo es abordar las vulnerabilidades individuales / sociales que se pueden generar por no atender a las necesidades no humanas. Utiliza como método la superposición de los conceptos de desarrollo, necesidades y vulnerabilidades, recurriendo a algunas disposiciones metodológicas de la teoría de la complejidad. Concluye sobre la importancia de los enfoques económicos se acercaren a la complejidad, utilizaren los nuevos indicadores de sostenibilidad y de valores humanos. Considera la proposición que afirma que cuando la economía cambia, el desarrollo cambia. Cuando el hombre cambia, la economía y el desarrollo también cambian.

Palabras clave: Vulnerabilidades. Necesidades. Desarrollo. Sostenibilidad.

\section{Introdução}

A proposta de uma economia verde divulgada na Conferência das Nações Unidas (Rio+20) chama a atenção para a necessidade de a economia transformar-se para que o desenvolvimento siga um caminho sustentável. A economia verde é definida como aquela que resulta na melhoria do bem-estar humano e da igualdade social, ao mesmo tempo em que reduz significativamente os riscos ambientais e as limitações ecológicas (PNUD, 2012).

O objetivo proposto é o de abordar vulnerabilidades sociais/ individuais possíveis de serem geradas pelo não atendimento de necessidades básicas, amparado na perspectiva inter e transdisciplinar da Economia Ecológica (EE).

O método utilizado vem da teoria da complexidade, em que é realizada a sobreposição dos conceitos de desenvolvimento, necessidades e vulnerabilidades, com a presença de novos indicadores de desenvolvimento e das principais organizações internacionais.

Para a realização desse propósito, no campo do que se pode chamar de economia com enfoque humano, apoia-se na construção 
teórica das necessidades humanas vinda de Maslow (1975), idealizador da Pirâmide das Necessidades; de Max-Neef (1992), idealizador da Matriz da Felicidade; de De Masi (2001), entendendo ser o tempo livre uma importante necessidade humana. Apoia-se ainda em: Sen (2000; 2001), que ressalta a liberdade (como uma necessidade humana) ligada à igualdade como condição e meio para o desenvolvimento; Schumacher (1983), por ressaltar valores humanos; Furtado (1984; 1996), no sentido de diferenciar desenvolvimento de crescimento econômico; Bosi (2012), que registra em seu artigo sobre a reconstrução da história da economia e do humanismo o importante, mas não reconhecido, movimento Economia e Humanismo, fundado pelo frade Joseph-Louis Lebret, propondo o reconhecimento das necessidades básicas na consolidação das comunidades para a reivindicação da satisfação dessas necessidades e redefinindo o ser humano concreto nas relações com a economia, com a política e com o Estado.

A parte 1 é a introdutória, a 2 aborda algumas das principais Organizações Internacionais (OI) e novos indicadores de desenvolvimento. A parte 3 apresenta conceitos de vulnerabilidade e descreve alguns elementos introdutórios da formação dos desejos e das necessidades. A parte 4 contempla brevemente o tema economia a partir de conceitos gerais, passando para o campo da complexidade para a economia. Na parte 5, apresenta-se uma junção dos elementos de desenvolvimento, vulnerabilidades e necessidades humanas, obtendo-se um parâmetro para estudos sobre insustentabilidade atrelados ao não atendimento das necessidades. Encerra-se com as conclusões.

\section{Organizações internacionais (OI) e os novos indicadores de Desenvolvimento Humano (DH) e Ecologicamente Sustentável (DeS)}

Organizações Internacionais (OI) são constituídas por meio de tratados ou acordos com a finalidade de incentivar a permanente cooperação entre seus membros, a fim de atingir objetivos comuns, entre eles, o de desenvolvimento. Indicadores de desenvolvimento dependem do que se entende pelo termo e, para diferenciar da 
ideia de crescimento, é sempre importante diferenciar a ideia de Desenvolvimento Econômico (DE) como aumento do PIB e, portanto, de crescimento da ideia de Desenvolvimento Humano (DH) e Desenvolvimento (ecologicamente) Sustentável (DeS) como aumento da qualidade de vida e do bem-estar. Isso porque a visão econômica generalizada no mundo (acadêmico, político, empresarial e social) ainda é a de que o PIB é um indicador de desenvolvimento.

0 atendimento de necessidades humanas representa o respeito aos direitos humanos, e o atendimento desses direitos representa o $\mathrm{DH}$ e, por consequência, o DeS. DeS diz respeito às questões globais, uma vez que as dinâmicas dos ecossistemas não respeitam fronteiras territoriais criadas pelo homem. Além dessa condição global, o DeS não se limita aos cuidados apenas com o meio natural biofísico externo ao humano, mas diz respeito também às necessidades da natureza humana - entre elas, a de viver em um meio natural saudável. Sendo global, é evidente a importância da atuação das Ol como orientadoras, reguladoras ou mesmo controladoras de caminhos sobre o desenvolvimento em um mundo globalizado.

As Ol foram fundadas após as trágicas atrocidades ocorridas durante a $2^{a}$ Guerra Mundial, mas suas raízes antecedem esse período. Em 1789, houve a Declaração dos Direitos do Homem e do Cidadão, proclamada na França, demonstrando que a liberdade é uma necessidade humana. Passaram-se mais de 150 anos e ainda nessa primeira década do século XXI há países onde muitos dos direitos humanos não são respeitados.

Somente em 1945, com a Carta das Nações Unidas, assinada inicialmente por 51 Estados membros originais (atualmente, 193), povos de diferentes culturas exprimiram sua determinação em respeitar os direitos fundamentais das pessoas: a dignidade e o valor humano. $\mathrm{Na}$ sequência, abriu o espaço para ser lançada a Declaração Universal dos Direitos Humanos (em 1948, nos Estados Unidos).

Desse movimento surgiram as Ol, sendo as mais relevantes para o presente estudo: A ONU (Organização das Nações Unidas), 
criada em 1945 com o objetivo de organizar as relações internacionais e assegurar a paz mundial diante de conflitos de ordens diversas, procurando representar a promessa de segurança às sociedades mundiais; a OIT (Organização Internacional do Trabalho), criada antes da ONU e acolhida por ela como sua primeira agência, com o objetivo de influenciar legislações trabalhistas com recomendações muitas vezes voltadas à diminuição da exploração do trabalho pelos interesses do mercado e tendo como pauta, na primeira década do século XXI, ainda em fase inicial de discussões, a redução da carga horária diária dos trabalhadores; a FAO (Organização das Nações Unidas para Agricultura e Alimentação), criada em 1945 objetivando negociar acordos, políticas e estratégias de erradicação da fome e da insegurança alimentar no mundo; envolve-se também com problemas de ordem ecológica na medida em que água e alimentos são dependentes de um meio ambiente saudável; a UNESCO (Organização das Nações Unidas para Educação, Ciência e Cultura), criada em 1945 com o objetivo de contribuir para a paz por meio da educação, da ciência e da cultura, visando eliminar o analfabetismo; a OMS (Organização Mundial da Saúde), fundada em 1948, subordinada à ONU, tendo por objetivo acompanhar e fornecer orientações para o desenvolvimento do nível de saúde de todos os povos, definindo a saúde não apenas como ausência de doença, mas como o estado completo de bem-estar físico, mental e social; e a OCDE (Organização para a Cooperação e o Desenvolvimento Econômico), fundada em 1961 em substituição à OECE (Organização Europeia para a Cooperação Econômica), com ações voltadas ao contexto econômico e à área das políticas sociais de educação, saúde, emprego e renda, atuando com fóruns internacionais a fim de articular políticas públicas (entre os países mais ricos do mundo) e voltada ao pensamento econômico neoclássico, em que resultados do PIB representam desenvolvimento.

Outras organizações com abrangência internacional e de cunho não governamental surgiram ao longo da segunda metade do século XX com propósitos de colaborar com o DH, como a Anistia Internacional (Al) fundada em 1961, atuante na divulgação e defesa dos direitos humanos, e o Greenpeace, fundado em 1971, atuando internacionalmente em questões relacionadas à preservação do meio ambiente e do desenvolvimento sustentável. 
A década de 1990 foi atuante no sentido de ações voltadas aos direitos humanos e aos cuidados com o meio ambiente. Foi a década do surgimento de novos indicadores de desenvolvimento procurando complementar as limitações, principalmente, do principal indicador das atividades econômicas, o PIB (Produto Interno Bruto), criado na década de 1940.

Entre os novos indicadores, está o IDH (Índice de Desenvolvimento Humano), procurando medir a qualidade de vida, inicialmente, por meio dos seguintes fatores: educação, longevidade e renda per capita, indicando algumas vulnerabilidades sociais diante do não atendimento a esses três restritos fatores. Posteriormente surgiu o IS (Índice de Sustentabilidade), o mais divulgado, a Pegada Ecológica, criado em 1996, método pioneiro que se propôs a contabilizar os fluxos de matéria e energia de um sistema convertendo-os em área correspondente de terra ou água existentes na natureza. O IVH (Índice de Valores Humanos), lançado como um complemento do IDH, procura retratar de forma qualitativa as vivências da população em relação à saúde, educação e ao trabalho, aplicado em algumas regiões brasileiras com o objetivo de identificar como as pessoas percebem o respeito, a liberdade, a reciprocidade e a convivência na sociedade. 0 ponto de partida do IVH é a ideia de que os valores são formados a partir das experiências das pessoas, por isso, o índice tenta captar a percepção dos indivíduos sobre situações vivenciadas no dia a dia (PNUD, 2010).

\section{Vulnerabilidade}

Vulnerabilidades podem ser observadas pela via ambiental (envolvendo ecossistemas e outras dinâmicas da natureza externas ao humano) e pela via social e individual (envolvendo diretamente a natureza humana).

A vulnerabilidade ambiental corresponde à resposta do meio às ações humanas, variando conforme suas características naturais e antropogênicas, afetando diretamentea estabilidade do meio, bem como sua qualidade ambiental (SANTOS; CALDEYRO, 2007). A vulnerabilidade 
ambiental é também entendida como a suscetibilidade do ambiente ao impacto provocado pela antropização. Já a vulnerabilidade social é entendida como a suscetibilidade das sociedades pela escassez de recursos em geral, gerando áreas de risco ambiental, aumentando a insegurança sobre a vida e agravando o atendimento de mais uma das necessidades do ser humano que é a de sentir-se em segurança (TAGLIANI, 2002).

A vulnerabilidade social é normalmente definida diante da existência de três situações: a exposição social/individual ao risco (fontes geradoras de insegurança física e emocional); a incapacidade de reação (no sentido de impotência diante de um fato vivido ou prospectado); e a dificuldade de adaptação diante da concretização do risco (conforme as limitações adaptativas da natureza humana) (MOSER, 1983).

Da relação entre natureza e sociedade, ambas em situações de risco, forma-se o que conhecemos como cumulatividade de riscos, formando a vulnerabilidade socioambiental (MOSER, 1983; MARANDOLA; HOGAN, 2005).

\section{a. Formação dos desejos e das necessidades}

Muitas das necessidades e dos desejos humanos foram descritos nas mais antigas escrituras da história humana e posteriormente fizeram parte de debates filosóficos na antiga Grécia. Na sequência, a ciência realizou pesquisas, construiu conceitos, dividiu o tema em diferentes setores do conhecimento e, de certa forma, o conhecimento sobre a natureza humana ficou esquartejado.

Uma das formas de compreensão sobre a formação dos desejos é descrita por Lacan (apud DOR, 1989), no sentido de que o desejo adquire voz no inconsciente e, embora pareça ser individual, é revelado pelo outro por meio do discurso do outro, na medida em que o sujeito humano é um efeito da linguagem. Definir o desejo como desejo do outro foi, para Lacan, instituir um princípio explicativo para as transformações sociais e culturais. 0 desejo demonstra a ausência 
do objeto desejado ou indica a presença da percepção da falta, ou seja, da necessidade. Em uma sociedade, essa percepção ocorre de forma dinâmica e em cadeia e sempre está amparada pelo que, de início, poucos percebem, mas, na medida em que a nova percepção é transmitida aos outros, o grupo humano passa a ter desejos semelhantes e assim novas culturas são formadas.

O sistema cultural como um elemento formador dos desejos e das percepções é capaz de ocultar algumas necessidades e criar outras. Foi o que ocorreu com a mimetização cultural consumista iniciada no século passado, quando algumas necessidades humanas foram abafadas pelos interesses do mercado e outras foram criadas.

Conforme observações de Adorno (1995), no século XX o sentido legítimo da cultura foi transgredido, e a cultura passou a se subordinar às leis de equivalência do mercado, o que criou uma cultura da produção e do consumo a qualquer custo. Tudo virou produto. A civilização que deveria transcender regrediu e se tornou consumivel, mimetizada, a ponto de esquecer algumas das suas reais necessidades básicas para o seu bem-estar e, de certa forma, houve uma espécie de desumanização do humano.

Ativar o processo de humanização é ampliar o desenvolvimento das capacidades cognitivas individuais das pessoas. Como resultado desse processo, pode ser ampliada a percepção individual/social sobre necessidades, bem-estar e/ou qualidade de vida.

Na Conferência de Ottawa, realizada pela OMS em 1986, a expressão qualidade de vida, assim como de saúde, foi definida como um completo bem-estar físico, mental e social (OMS, 1986), de acordo com as necessidades humanas atingidas. No documento resultante dessa conferência, a Carta de Ottawa declara que são os indivíduos e grupos sociais quem devem saber identificar suas aspirações e satisfazer suas necessidades (Ibidem).

Uma das abordagens teóricas mais difundidas sobre necessidades humanas foi desenvolvida por Maslow (1975), em um 
sentido hierárquico de necessidades, obedecendo a uma escala de valores a serem transpostos. Na base estão as fisiológicas, seguidas das de segurança, sociais, de status e estima e de autorrealização. Esses cinco grupos de necessidades englobam três tipos de motivos: 1) os físicos, 2) os de interação com os outros e 3) os relacionamentos com o self(Ibidem). A prioridade dada para as necessidades fisiológicas, formando a base da pirâmide das necessidades, não pode ser muito questionada; entretanto, a ordem das demais pode ser discutivel se a análise se der a partir de uma visão da complexidade e, nesse sentido, elas relacionam-se como em rede e não em hierarquias piramidais.

As mais básicas, as físicas ou fisiológicas, responsáveis pelo bom funcionamento do corpo, são: as necessidades de alimentação (incluindo água); de ar; de excreção; da homeostase; de abrigo; e de descanso (além da energia solar).

As três primeiras necessidades (alimento, ar e excreção) explicam o corpo humano (com vida) como um sistema aberto que permanentemente troca matéria e energia com o ambiente externo. A homeostase, uma espécie de vontade própria da natureza, é "a habilidade de um indivíduo manter as condições internas constantes em face de um ambiente externo variante" (RICKLEFS, 1996, p. 145). 0 estado de equilíbrio das diversas funções e composições químicas do corpo, como a temperatura, o pulso, a pressão arterial, a taxa de açúcar no sangue, etc., depende da capacidade de resiliência do corpo. Essa capacidade descreve o montante de distúrbio que pode ser absorvido pelo corpo (ou pelos ecossistemas), assim como a velocidade do retorno ao estado de equilíbrio (uma vez eliminados os distúrbios), antes que ocorra uma mudança fundamental na sua estrutura ou que provoque os sintomas de doenças (ou os sérios desequilíbrios).

A necessidade de abrigar o corpo está relacionada à homeostase e à segurança. O corpo humano recebe influências da temperatura e trabalha para o alcance de um equilíbrio que o mantenha vivo. Segundo Mendonça, "o clima é um dos principais fatores a influenciar os diferentes tipos de adaptações do homem na superfície do planeta, podendo influenciá-lo positiva ou negativamente" e a sensibilidade humana ao clima, enquanto temperatura do ar, se muito elevada 
ou muito baixa, é também um dos elementos estimulantes da agressividade humana (MENDONÇA, 2001, p. 23). Além da relação do abrigo com o clima, podendo gerar vulnerabilidades individuais/sociais, a necessidade de abrigar o corpo envolve também a necessidade da segurança física diante dos perigos que possam o atingir. A insegurança ou a vulnerabilidade do corpo sem abrigo ou com abrigo inadequado pode provocar alterações psicológicas, interferindo no comportamento humano da mesma forma como ocorre a homeostase como defesa fisiológica do corpo humano diante da temperatura.

Dessa reação natural há efeitos ou estímulos no comportamento para a realização do bem-estar ou do conforto térmico. Sobre esse assunto, Ayoade (1996) considera que, na medida em que as condições climáticas diferem espacialmente e influenciam no metabolismo do corpo humano, surge uma questão já estudada, principalmente pelos climatólogos, no sentido das interfaces e complementaridades entre clima e sociedade, clima e comportamento, envolvendo a correlação clima e bem-estar ou clima e mal-estar. Segundo Ayoade:

\footnotetext{
Ainda que se reconheça que o aspecto climático seja apenas uma parcela do grande enfoque do bem-estar humano, a saúde humana, a energia e o conforto são afetados mais pelo clima do que por qualquer outro elemento do meio ambiente. O conforto fisiológico do homem é determinado, principalmente, pela temperatura, pelo vento e pela umidade (1996, p. 189-0).
}

A necessidade de descanso, no sentido físico, também desencadeia no corpo reações homeostáticas. A defesa do corpo diante do esgotamento físico é o sono, uma necessidade citada pela OMS como a terceira mais importante necessidade básica para a saúde, seguida da água e do alimento.

Outras descrições das necessidades humanas vêm de MaxNeef (1986) e Lebret (apud BOSI, 2012). Max-Neef (1986) salientou a necessidade de subsistência, de proteção, de compreensão, de participação, de lazer, de criação, de expressão da liberdade e da identidade, do exercício do afeto, do amor e do ócio, classificadas em duas categorias: a existencial e a axiológica. 
Lebret (apud BOSI, 2012) classificou as necessidades como pessoais e coletivas. Nas pessoais estariam as conhecidas pela biologia como básicas; quando não satisfeitas em seus limites máximos, promovem a morte. Chamou de comodidades domésticas os serviços de água, luz e aquecimento; e de comodidades externas os serviços principais de um bairro. Elencou também como necessidade um trabalho regular e uma vida cultural e social, incluindo na educação a leitura, o conhecimento histórico, político e religioso. Em uma segunda classe de necessidades pessoais, elencou a dignidade (incluindo o espaço para se receber os amigos) e o conforto psíquico e social do ser humano. Como necessidade cultural incluiu o domínio de uma arte e a capacidade de compreender uma obra literária. Quanto às necessidades pessoais ou terciárias, entendeu que os seres humanos devem ser capazes de desenvolver ao máximo as suas capacidades (Ibidem), para que ocorra o que podemos entender como desenvolvimento humano.

Conforme são as indicações dos estudos apresentados sobre as necessidades para a saúde e o bem-estar, o tempo livre e com qualidade é um elemento-chave. Lebret considerou o tempo livre para pensar, estudar, meditar, contemplar, criar obras de arte e orar, o que é travado pelo excesso de trabalho bruto ou burocrático e o aguilhão dos cuidados materiais (Ibidem). Nessa mesma linha está De Masi (2001) em seu livro "Economia do Ócio", que tratou da necessidade de tempo para o ócio considerando que a sociedade já teria passado da fase industrial e estaria em uma fase pós-industrial. Nesta, o centro da economia deslocar-se-ia da produção de bens materiais para bens imateriais, ou seja, para uma economia que valorizasse novas ideias e analisasse melhor ou de forma mais complexa as necessidades humanas (DE MASI, 2001). Também Max-Neef inclui a necessidade de tempo ocioso para a realização de atividades da vida que estão além do que o mercado pode proporcionar.

Enquanto no passado o tempo livre, por existir naturalmente na vida das pessoas, não era considerado como uma necessidade, na medida em que o novo modelo industrial impôs mais atividades ao humano, ocupando mais o tempo de vida das pessoas, a própria sociedade industrial (chamada equivocadamente de desenvolvida) 
adotou culturalmente a ideia de que o tempo livre é algo negativo a ser desprezado, ligado a pessoas aposentadas, desempregadas ou desocupadas. Entretanto, tempo livre é necessário para a realização com liberdade das necessidades sensíveis, como de interação com os outros e os relacionamentos com o self (MASLOW, 1975); para o exercício do afeto, do lazer, da criação, da participação, da proteção e do próprio ócio (LEBRET apud BOSI, 2012), podendo o ócio ser apenas o deitar em uma rede e meditar (MAX-NEEF, 1992), realizar uma leitura, uma oração, estudos informais; em suma, para a realização da instrução (LEBRET apud BOSI, 2012).

Eibl-Eibesfeldt (1970), em “Amor e o Ódio”, concluiu que se há um instinto da agressividade inato no humano há também um forte impulso contrário e que as potencialidades do bem são biologicamente tão nossas como as do autoconhecimento. Sem o sentimento de amor, os sentimentos agressivos prevalecem e o oposto também é verdadeiro. Enquanto os sentimentos ligados ao amor são o cuidado com o outro, a amizade e a simpatia, os sentimentos que rompem ligações sentimentais são a ganância, a disputa e a agressividade. Tema também desenvolvido no século XVIII por Adam Smith em Teoria dos Sentimentos Morais (SMITH, 2002), quando desde o início da formação do funcionamento do sistema econômico já percebia a importância dos sentimentos de simpatia para o bem-estar social e dos sentimentos da ganância e do egoísmo como construtores do mal-estar.

Embora na condição humana coexistam os impulsos para o bem (paz, tranquilidade, amor) e para o mal (agressividade, ódio, elementos que geram insegurança), Eibl-Eibesfeldt (1970) conclui que a cultura é capaz de estimular, reprimir ou redirecionar tais impulsos. Considerou que a sociedade humana moderna perdeu muito dos significados primitivos da agressividade; entretanto, na base dos comportamentos, a condição biológica da espécie não desapareceu, pois as necessidades básicas não desapareceram. Afirma que a não possibilidade de liberar o impulso negativo acumulado (da insatisfação diante do não atendimento de necessidades biológicas) pode levar a comportamentos agressivos em busca da liberação desse impulso, o que amplia a vulnerabilidade individual/social. 
Ainda sobre a agressividade, Freud (1950 apud EIBLEIBESFELDT, 1970) entendeu que, embora não seja possível suprimi-la da condição humana, é possível neutralizá-la pela ativação de todas aquelas forças que atendam às necessidades básicas humanas e aquelas que estabeleçam as ligações sentimentais entre os seres humanos, ou seja, tudo aquilo que produz pontos comuns significativos entre homens estimula tais sentimentos de comunidade, e a estrutura da sociedade humana se assenta em grande parte sobre esses sentimentos (Ibidem).

\section{Economia}

A economia é o estudo da escassez para o atendimento das necessidades humanas. Surgiu com a denominação de economia política, como o ramo do conhecimento essencialmente voltado para a administração e o fortalecimento do Estado. A partir de Adam Smith, o foco da economia política passou do Estado para o indivíduo.

Smith e Hume (apud HEILBRONER, 1996) buscavam a racionalização do mundo social e acreditavam que a economia política deveria descobrir os princípios que fundamentariam a obtenção da felicidade humana - e isso se daria pelo estudo do homem e de suas motivações.

No final do século XIX, Marshall (1996) considerou cruciais os conceitos de riqueza e bem-estar social para a economia. Os pontos fundamentais dessa abordagem foram de que as necessidades e os desejos humanos são inúmeros e de várias espécies e as mudanças nos estágios culturais das sociedades organizadas definiriam as transformações dos desejos. Compreendeu que, de um lado, a economia seria um estudo da riqueza a partir do uso de recursos naturais e, de outro, seria o estudo do homem. No centro, estaria a atividade econômica com todas as relações entre produção e consumo, geração de empregos, circulação da renda, decisões de investimentos.

Diante da complexidade em se compreender a natureza humana e do esquartejamento do conhecimento, a economia limitou- 
se mais às relações internas do sistema econômico, como a velocidade da circulação da moeda, o aumento da produção, a geração de empregos e todos os intrincados cálculos que exigem as relações produção e consumo e a definem como economia neoclássica, mas deixando de lado o centro do estudo da natureza humana e a consideração de que o meio natural possui vida e uma lógica própria.

Essa compreensão foi mantida e continua na atualidade em livros de economia, com abordagens neoclássicas, a exemplo de Mankiw (2003), em que os dois polos das naturezas (humana e não humana) permanecem nas definições, mas na prática são apenas as engrenagens necessárias para que o sistema econômico mantenhase em funcionamento, e, quanto mais autômatos, melhor para a economia. Daí as profundas divergências entre a vertente neoclássica e a ecológica da economia, pois, na medida em que esses dois polos que mantêm o sistema econômico em funcionamento são compostos por elementos vivos, ao considerá-lo como tal em sua complexidade muitas das robustas teorias neoclássicas se esvaziam.

\section{a. A complexidade para a economia}

Não há uma teoria específica que trate da complexidade para a economia nem da economia como uma ciência complexa. Nesse sentido, o que ampara estudos sobre a complexidade para um desenvolvimento sustentável depende de compreender primeiramente a própria complexidade da vida.

Conforme descreveu Japiassu (1976; 1977), a busca em dissolver o reducionismo abriu espaços para o surgimento de uma epistemologia crítica sobre a responsabilidade social dos cientistas e dos teóricos na construção do conhecimento. Dessa busca surgiram a complexidade e as possibilidades de enfrentar problemas humanos complexos, como a difícil tarefa de transição de todo um modelo de desenvolvimento para outro, sobre a qual a economia chamada de verde pretende deixar a sua contribuição.

Morin (1995) observa que a própria ciência nos ensinou a separar e isolar as coisas a serem investigadas, pois não há como dar 
conta do todo, mas negar a complexidade pelas dificuldades que ela apresenta não resolve problemas complexos. Um exemplo dado por Morin (1995) remete-se diretamente à economia, ou seja, trata-se da ciência humana mais sofisticada no plano matemático e formal, mas incapaz de atuar sozinha sobre as várias crises que o sistema econômico apresenta de tempos em tempos.

Morin (1995) e Morin e Prigogine (1996), assim como outros cientistas que enfrentaram o problema da complexidade na ciência, entenderam que no interior das teorias há um núcleo obscuro que envolve interesses diversos, muitas vezes mais preocupado com a objetividade científica do que com a realidade complexa das coisas. Argumentaram que "a cientificidade é a parte emersa de um iceberg profundo de não cientificidade" (MORIN; PRIGOGINE, 1996, p. 18). A descoberta de que a ciência não é totalmente científica é, para Morin, uma grande descoberta científica que a maior parte dos cientistas ainda não percebeu.

Esse reconhecimento reforça a importância de pesquisas voltadas às racionalidades substantivas (SERVA, 1996) ou o que Morin e Prigogine (1996) chamam de racionalidade aberta, complementares às instrumentais; estas configuram-se como alternativas teóricometodológicas para uma nova economia, em que são revistas as condições de homo consumus e homo ecconumus, em um sentido de resgate do homo sapiens e podendo colocar a economia em uma condição de humana e ecológica.

Horkheimer (1976), embora considerado por alguns como polêmico, defendeu a junção das racionalidades, a instrumental e a subjetiva, e ainda postulou sobre a necessidade de ultrapassar o positivismo, no qual se buscam critérios de verdade apenas operacionais e de dominação e, dessa forma, incapazes de perceber outras racionalidades. Conforme argumentos de Horkheimer (1976), uma sociedade viva e crítica, de tempos em tempos, age a partir da ampliação da consciência sobre as resignações/vulnerabilidades sentidas e, assim, anuncia necessidades de mudança. Nessa perspectiva teórica, as mudanças projetadas para um novo modelo de 
desenvolvimento saem do campo do positivismo e entram no campo das complexidades.

A concepção da complexidade sugere o desafio e a motivação para pensar e é, antes de tudo, "o esforço para conceber um incontornável desafio que o real lança a nossa mente" (MORIN, 1999, p. 176). Um exemplo dado para se perceber a complexidade é de que "se tentamos pensar no fato de que somos seres ao mesmo tempo físicos, biológicos, sociais, culturais, psíquicos e espirituais, é evidente que a complexidade é aquilo que tenta conceber as articulações, a identidade e a diferença de todos os aspectos"; nesse sentido, a ambição da complexidade é "prestar contas das articulações despedaçadas pelos cortes entre disciplinas, entre categorias cognitivas e entre tipos de conhecimento". A complexidade não é uma proposta que pretenda "dar todas as informações sobre um fenômeno estudado, mas respeitar suas diversas dimensões [...] este é um princípio de incompletude e de incerteza" (MORIN, 1999, p. 177).

Édentrodessa concepção que residea EE, como uma abordagem complexa, inter e transdisciplinar. Piaget (1970) foi o primeiro a tratar da expressão transdisciplinaridade; Nicolescu (1999) apresentou o Manifesto da Transdisciplinaridade e diversos outros estudos; e Morin (1995) desenvolveu a Teoria da Complexidade.

A relação de pesquisadores adeptos à linha da EE é extensa e em crescimento constante. Cavalvanti (2010) apresenta uma relação, classificando-os, na medida do possivel, pelas linhas dos estudos desenvolvidos, e também apresenta uma listagem de nomes de economistas ecológicos organizada por Alier (2007), o que dá um amplo formato de referências bibliográficas da EE. Vale lembrar que todos têm como denominador comum a defesa de um modelo de desenvolvimento ecológico e socioeconômico sustentável.

A EE percebe o sistema econômico como um subsistema de um sistema ecológico maior e dedica-se às relações das leis da termodinâmica com a economia e com as lógicas de funcionamento dos sistemas naturais, destacando a dimensão e a dependência de cada um desses sistemas (GEORGESCU-ROEGEN, 1975). 
Além da relação do sistema econômico com os sistemas naturais não humanos, a $E E$ abre espaços para se perceber a dimensão humana do sistema econômico, mas não mais como uma engrenagem a alimentá-lo, e sim como a sua razão de ser. Ao colocar o humano como superior ao econômico, invertem-se as lógicas do pensamento neoclássico, ou seja, não serão mais as coisas que exigirão determinados comportamentos e necessidades das pessoas, e sim as pessoas serão as definidoras das suas necessidades, de seus comportamentos e do comportamento do sistema econômico. Para isso, é essencial que pessoas tenham a percepção sobre suas reais necessidades, seus direitos e suas capacidades, e, dessa forma, sejam as legítimas autoras de um desenvolvimento sustentável, capazes de gerar qualidade e bem-estar às suas vidas.

De forma global, o fortalecimento do campo humano da EE vem recebendo apoio das ações das organizações internacionais na medida em que direitos humanos estão cada vez mais sendo divulgados e, com eles, ampliando-se a percepção sobre as reais necessidades humanas. Os importantes debates entre EE versus abordagens neoclássicas são crescentes na medida em que novos indicadores vêm demonstrando e confirmando a insustentabilidade socioambiental - e, com ela, as vulnerabilidades socioambientais.

Essas afirmações encontram amparo nas conclusões presentes na Agenda XXI (1992), que diz que o êxito de um desenvolvimento sustentável é dependente de que se modifiquem comportamentos e estilos de vida, que ocorram mudanças de valores, de preceitos culturais e de morais arraigados, da ampliação da percepção individual e social sobre desenvolvimento, em que a conduta humana se fundamenta.

A noção de desenvolvimento alheia ao pensamento neoclássico pode também ser amparada na descrição de Furtado (1984) ao afirmar que as sociedades são consideradas desenvolvidas na medida em que nelas o homem consegue satisfazer suas necessidades, manifestar suas aspirações e exercer seu gênio criador. Desenvolvimento é:

[...] um processo criativo, de invenção da História pelos homens, em contraste com o quadro mimético e repetitivo de que são prisioneiras as 
sociedades dependentes. [...] o desenvolvimento é menos o domínio da natureza e mais um processo de criação de valores, portanto, de avanço na racionalidade substantiva ou dos fins (FURTADO, 1984, p. 63).

Em outras definições de desenvolvimento também são evidentes as relações com o atendimento das necessidades da natureza humana. Entre elas, estão a de: Cavalcanti (2001), definindo desenvolvimento como a realização de certos objetivos de valor para o engrandecimento do ser humano a partir de uma visão integrada de variáveis ecológicas, econômicas e sociais, ao lado de aspectos biológicos, físicos, políticos, institucionais e culturais, sem esquecer anteparos éticos e filosóficos; Schumpeter (1997), ao entender que desenvolvimento é mudança, o novo, significando evolução, transformação; Sen (2000), ao identificar que desenvolvimento é o exercício da liberdade individual e das capacidades humanas e como um processo de expansão das liberdades substantivas das pessoas. As liberdades não são os fins primordiais do desenvolvimento, mas os meios principais. Também Furtado (1996) define desenvolvimento como menos o domínio da natureza e mais um processo de criação de valores, de avanço na racionalidade substantiva. Da mesma forma Schumacher (1983) observa que o desenvolvimento representa dar ao homem a oportunidade de utilizar e desenvolver suas faculdades, entre elas, a criatividade artística, em um aperfeiçoamento progressivo do bem-estar a partir da realização de novas capacidades e potencialidades verdadeiramente humanas.

Diante de tais definições, insustentável é tentar alcançar o DH e DS a partir do bom desempenho do PIB e excluindo o que os novos indicadores de IDH e, principalmente, o IVH podem demonstrar.

\section{A insustentabilidade e o não atendimento de necessidades}

A essência e o desafio do conceito de sustentabilidade ecológica são a manutenção de estoques físicos de capital natural (não degradado) e o atendimento das necessidades humanas ou a essência da insustentabilidade, o encontro da redução irreversível dos estoques 
naturais com a ampliação das vulnerabilidades individuais/sociais. 0 não atendimento das reais necessidades humanas é um dos principais fatores das vulnerabilidades socioambientais (fonte geradora da insegurança), enquanto a corrida pelo atendimento de todas as necessidades criadas pela cultura consumista é observada como um dos motivos da insustentabilidade do modelo de desenvolvimento/ crescimento adotado na grande maioria dos países.

O acompanhamento da evolução das condições socioambientais do desenvolvimento depende dos dados dos novos indicadores já criados (IDH, IS, IVH), mas ainda em fase de implantação de mais variáveis e abrangência. Anualmente, são lançados relatórios diversos organizados pelas Ol a fim de registrar e divulgar as condições da vida global.

Dados globais relacionados à distribuição de alimentos, de água potável e de doenças que mais atingem as sociedades, ou mesmo dados sobre a violência, são algumas das informações que podem ser contrapostas às definições de necessidades humanas, vulnerabilidades e desenvolvimento.

Segundo dados da FAO (2011), aproximadamente 925 milhões de pessoas no mundo não têm acesso à alimentação necessária para serem consideradas saudáveis; a fome está na lista dos 10 maiores riscos de vida e é o que mais mata pessoas anualmente, mais do que a AIDS, a malária e a tuberculose juntas (OMS, 2012).

No Brasil, 40 milhões de pessoas convivem com a forma leve de insegurança alimentar, 14 milhões estão na situação moderada e 11 milhões passam pela privação de alimentos, considerada como grave insegurança alimentar (IBGE, 2012). No entanto, há um excesso do consumo de alimentos, gerando problemas de obesidade presentes em várias sociedades e o Brasil não escapa desse diagnóstico, além do excesso de desperdício de alimentos - cerca de 1,3 bilhões de toneladas de alimentos são perdidos, conforme mostra o relatório da ONU (FAO, 2011). 
Relatórios da ONU repetem diagnósticos declarando que mais de um bilhão de pessoas não têm acesso a uma quantidade mínima aceitável de água potável, e estima-se que em 2025 mais de cinco bilhões de pessoas estarão nessa estatística. No Brasil, de acordo com relatório elaborado pela Agência Nacional de Águas (ANA, 2012), apesar do aparente conforto em reservas hídricas, a distribuição espacial é desigual. Cerca de $80 \%$ da disponibilidade hídrica está na Amazônia, onde se encontra o menor contingente populacional, e 47\% das águas em áreas urbanas foram avaliadas como ruins ou péssimas, dado o baixo índice de coleta e tratamento de esgoto; constatou-se, ainda, que apenas 45,7\% dos domicílios brasileiros possuem acesso à rede de esgoto. Dos 5.565 municípios brasileiros, mais da metade poderá ter déficit no abastecimento de água em 2015 pela falta de investimentos para a adequação dos sistemas produtores de água potável. Além de a água ser essencial para a manutenção da vida (humana e não humana), também é essencial para o setor industrial, gerador de empregos e renda, e, mesmo assim, nem mesmo medidas básicas de saneamento, de coleta e destino do lixo, estão resolvidas e ainda não há uma percepção social geral sobre esses serem os investimentos públicos mais primordiais.

Conforme relatório do Ministério das Cidades (2011), para o Brasil resolver apenas o problema relacionado ao saneamento básico será necessário investir $\mathrm{R} \$ 420,9$ bilhões em medidas estruturais e estruturantes, porém, considerando-se que investimentos públicos anuais são divididos em vários segmentos e a prioridade de investimentos é um resultado da pressão social e da eficiência política, dependente da percepção individual e social das suas próprias necessidades, sem tal percepção não há a pressão social necessária e, nesse quadro, a perspectiva para a totalização desse investimento é de 20 anos.

A insônia foi diagnosticada pela OMS (2011) como o problema de saúde mais comum no mundo e uma série de diagnósticos apontam para alterações comportamentais e o aumento da agressividade quando o sono é prejudicado. As causas da insônia podem ser várias, mas a mais evidente e citada pela OMS é o estresse (divulgado em 
2008, também pela OMS, como a epidemia do século). A depressão, a poluição sonora, a fome, a falta de moradia digna, a falta de segurança e a falta de tempo também são fontes causadoras da insônia.

A necessidade de descanso é prejudicada pela cultura consumista estabelecida no século passado que impõe às pessoas mais o ter do que o ser. Essa falta de tempo para as atividades sensiveis, sociais, psicológicas ou apenas para o descanso mental (ócio) gera a insônia e o estresse.

Com o aumento populacional e a concentração de pessoas em centros urbanos, com jornadas de trabalho muitas vezes ultrapassando oito horas diárias, com a ineficiência da mobilidade urbana e dos serviços de transporte coletivo e diante da ineficiência do setor público e privado em atender às demandas pelos serviços sociais (bancários, de telefonia, de saúde e outros), o tempo para a prática da vida é reduzido. Nesse sentido, as filas de atendimento, filas para o transporte, filas diversas podem ser consideradas como algo insustentável para o bem-estar e para a qualidade de vida das pessoas, e esse também é um forte indicativo para definições de prioridades políticas para o desenvolvimento humano.

A agressividade e a violência no mundo atual são medidas de acordo com registros em delegacias e pelo tamanho da população carcerária, mas não são medidas pela falta de atendimento das necessidades humanas. O sistema carcerário brasileiro está entre os piores e mais desumanos do mundo (GRECCO, 2010), e, conforme análises do referido autor, há ainda uma cultura social de que presos não devem ter direitos humanos, o que de certa forma reforça o não atendimento das suas necessidades e amplia ainda mais o problema na medida em que eles retornam à sociedade.

\section{Conclusão}

No mundo globalizado, evidencia-se a importância das Ol como orientadoras, reguladoras ou mesmo controladoras de caminhos para 
o desenvolvimento, que deveria levar em conta as reais necessidades humanas e um ambiente saudável para viver com qualidade, com minimização das vulnerabilidades.

O sistema cultural como um elemento formador dos desejos e das percepções é capaz de ocultar algumas necessidades e criar outras, assim como aconteceu na atual cultura da produção e do consumo a qualquer custo, em que tudo é considerado mercadoria. Contudo, as reais necessidades vão além daquelas consideradas básicas, pois outras, como a compreensão, participação, o lazer, a criação, a expressão da liberdade e da identidade, o exercício do afeto, o amor e o ócio, ou seja, ter tempo para pensar, estudar, meditar, contemplar, criar obras de arte e orar, também se fazem necessárias para o bem-estar de todos.

Do ponto de vista da economia ecológica, não há como atingir o desenvolvimento sustentável a partir do pensamento neoclássico. Essa ciência, que naturalmente deveria ser interdisciplinar, ao ter sido enquadrada em moldes disciplinares e seus interesses reduzidos muito mais às dinâmicas mecânicas do funcionamento do mercado, acabou por não conseguir gerar um desenvolvimento com fisionomia humana e sustentável. A economia nos moldes neoclássicos, ao se debruçar na busca por um rigor matemático, elimina das suas abordagens tudo o que diz respeito à vida e às suas complexas relações e articulações. Assim, torna-se ineficiente a ponto de estar no centro do furacão chamado desenvolvimento insustentável. Com as suas simplificações, a cada resolução de um problema, cria outros a serem solucionados no futuro. Todo esse conhecimento é dotado de grande complexidade e por isso demanda outras abordagens para o seu entendimento e compreensão. A falta de percepção social sobre as consequências negativas do não atendimento às necessidades da natureza humana interfere na qualidade de vida de todos.

Recebido 20/09/2012

Aprovado 25/07/2013 


\section{Referências bibliográficas}

ADORNO, T. W. Educação e Emancipação. Rio de Janeiro: Paz e Terra, 1995.

AGENDA XXI. Conferência das Nações Unidas sobre Meio Ambiente e Desenvolvimento. Rio de Janeiro: 1992. 2. ed. Brasília: Senado Federal, 1997.

ALIER, J. M. Economia e Ecologia: questões fundamentais. Tradução Mauricio Waldman. São Paulo: Contexto, 2007.

ANA - Agência Nacional de Águas. Conjuntura dos recursos hídricos no Brasil: informe 2012. ed. especial. Brasília: ANA, 2012.

AYOADE, J. O. Introdução à Climatologia para os trópicos. 4. ed. Rio de Janeiro: Bertrand Brasil, 1996.

BOSI, A. Economia e humanismo. Estudos Avançados, São Paulo, v. 26, n. 75, maio/ago. 2012. Disponivel em: <http://www.scielo.br/scielo. php?script=sci_arttext\&pid=S0103-40142012000200017\&Ing=pt\&nr m=iso\&tlng=en>. Acesso em: 10 ago. 2012.

CAVALCANTI, C. Pensamento econômico, saber ecológico tradicional e etnoeconomia: uma proposta introdutória de nova perspectiva disciplinar. Recife: Instituto de Pesquisas Sociais, Ed. Fundação Joaquim Nabuco, 2001

Concepções da economia ecológica: suas relações com a economia dominante e a economia ambiental. Estudos Avançados, São Paulo, v. 24, n. 68, 2010.

DE MASI, D. A economia do ócio. Rio de Janeiro: Sextante. 2001.

DOR, J. Introdução à Leitura de Lacan, O Inconsciente Estruturado como Linguagem. Porto Alegre, RS: Artmed Editora, 1989. 
EIBL-EIBESFELDT, I. Amor e Ódio: História Natural dos Padrões Elementares do Comportamento. Lisboa: Livraria Bertrand, 1970.

FAO - Organização das Nações Unidas para Agricultura e Alimentação. Publicações. 2011. Disponivel em: <https://www.fao.org.br/ publicacoes.asp>. Acesso em: 03 ago. 2012.

FURTADO, C. Cultura e Desenvolvimento em época de crise. Rio de Janeiro: Paz e Terra, 1984.

0 mito do desenvolvimento econômico. Rio de Janeiro: Paz e Terra, 1996.

GEORGESCU-ROEGEN, N. Energy and the economic myths. Southern Economic Journal, v. 41, n. 3, 1975.

GRECCO, R. Direitos Humanos e Sistema Prisional. TVLFG, 30 set. 2010. Disponivel em: <http://www.youtube.com/watch?v=JhpVSaavBB8>. Acesso em: 12 maio 2012.

HEILBRONER, R. L. A história do pensamento econômico. 6. ed. Coleção Os Economistas. São Paulo: Nova Cultural, 1996.

HORKHEIMER, M. Eclipse da razão. Rio de Janeiro: Labor, 1976.

IBGE - Instituto Brasileiro de Geografia e Estatística. Segurança Alimentar. Disponivelem:<http://www.ibge.gov.br/home/estatistica/ populacao/trabalhoerendimento/pnad2004/suplalimentar2004/>. Acesso em: 20 ago. 2012.

JAPIASSU, H. F. Interdisciplinaridade e patologia do saber. Rio de Janeiro: Imago, 1976.

Introdução ao pensamento epistemológico. 2. ed. Rio de Janeiro: Francisco Alves, 1977.

MANKIW, M. N. G. Introdução à Micro e à Macroeconomia. Rio de Janeiro: Campus, 2003. 
MANANDOLA, E.; HOGAN, D. J. Vulnerabilidade e riscos: entre Geografia e demografia. Revista Brasileira de Estudos de População, São Paulo, v. 22, n. 1, p. 29-53, 2005.

MARSHALL, A. Princípios de Economia. São Paulo: Nova Cultural, 1996.

MASLOW, A. H. Uma teoria da motivação humana. In: BALCÃO, Y.; CORDEIRO, L. L. (Orgs.). 0 comportamento humano na empresa. Rio de Janeiro: FGV, 1975. p. 337-366.

MAX-NEEF, M. Economía Descalza. Señales desde el mundo invisible. Tradução de Stela Lorca. Colección Pensamiento Descalzo. Montevideo: Nordam Comunidad, 1986.

. Chamar Desenvolvimento a um Suicídio Colectivo. A Rede para

o Desenvolvimento Local, n. 7, p. 18-27, dez. 1992.

MENDONÇA, F. Clima e criminalidade: Ensaio analítico da correlação entre a temperatura do ar e a incidência de criminalidade urbana. Curitiba: UFPR, 2001.

MINISTÉRIO das Cidades. Panorama do saneamento básico no Brasil. v. 5. 2011. Disponivel em: <http://www.saneamentoweb.com.br/ sites/default/files/PANORAMA_Vol_1.pdf>. Acesso em: 08 jul. 2012.

MORIN, E. Introdução ao pensamento complexo. 2. ed. Lisboa: Instituto Piaget, 1995.

O Método Il: A vida da vida. 3. ed. Portugal: Publicações EuropaAmérica, LDA, 1999.

MORIN, E.; PRIGOGINE, I. A Sociedade em Busca de Valores. Lisboa: Instituto Piaget, 1996.

MOSER, A. O problema ecológico e suas implicações éticas. Petrópolis, RJ: Vozes, 1983. 
NICOLESCU, B. O Manfesto da Transdisciplinaridade. São Paulo: Triom, 1999.

OMS-Organização Mundial da Saúde. Carta de Ottawa. 1986. Disponível em: <http://www.mpba.mp.br/atuacao/cidadania/gesau/legislacao/ internacionais/carta_ottawa.pdf>. Acesso em: 28 dez. 2005.

World Health Statistics 2011. 2011. Disponivel em:

<http://www.who.int/whosis/whostat/2011/en/index.html>. Acesso em: 01 ago. 2012.

O que você precisa saber sobre a fome em 2012. 2012. Disponivel em: <http://www.onu.org.br/o-que-voce-precisa-sabersobre-a-fome-em-2012/>. Acesso em: 01 ago. 2012.

PIAGET, J. Problemas gerais da investigação interdisciplinar e mecanismos comuns. Tradução de Maria Barros. Paris: Bertrand, 1970.

PNUD - Programa das Nações Unidas para o Desenvolvimento. Novo indicador do RDH retrata vivências no trabalho, na educação e na saúde. 2010. Disponível em: <http://www.pnud.org.br/Noticia. aspx?id=2377>. Acesso em: 12 mar. 2012.

Rumo a uma economia verde. Caminhos para o Desenvolvimento Sustentável e a Erradicação da Pobreza. 2012. Disponivel em: <http://www.pnuma.org.br/admin/publicacoes/ texto/1101-GREENECONOMY-synthesis_PT_online.pdf>. Acesso em: 28 ago. 2012.

RICKLEFS, R. A Economia da Natureza. 3. ed. Tradução de Cecília Bueno e Pedro P. de Lima e Silva. Rio de Janeiro: Guanabara, 1996.

SANTOS, R. F.; CALDEYRO, V. S. Vulnerabilidade Ambiental: desastres ambientais ou fenômenos induzidos?. In: SANTOS, R. F. (Org.). Vulnerabilidade Ambiental: desastres ambientais ou fenômenos induzidos? Brasília: MMA, 2007. 
SCHUMACHER, E. F. O negócio é ser pequeno: um estudo de economia que leva em conta as pessoas. 4. ed. Tradução Octávio Alves Velho. Rio de Janeiro: Zahar, 1983.

SCHUMPETER, J. A. Teoria do Desenvolvimento Econômico: uma investigação sobre lucros, capital, crédito, juro e o ciclo econômico. São Paulo: Nova Cultural, 1997.

SEN, A. Desenvolvimento como Liberdade. São Paulo: Cia das Letras, 2000.

Desigualdade reexaminada. Rio de Janeiro: Record, 2001.

SERVA, M. R. Racionalidade e Organizações: O fenômeno das organizações substantivas. São Paulo: Fundação Getúlio Vargas, 1996.

SMITH, A. Teoria dos Sentimentos Morais. 2. ed. São Paulo: Editora Martins Fontes, 2002.

TAGLIANI, C. R. A mineração na porção média da Planície Costeira do Rio Grande do Sul: estratégia para a gestão sob enfoque de Gerenciamento Costeiro Integrado. 2002. 252p. Tese (Doutorado em Geociências)Programa de Pós-Graduação em Geociências, Universidade Federal do Rio Grande do Sul, Porto Alegre, 2002. 